Dai et al., Afr J Tradit Complement Altern Med., (2017) 14 (3): 12-21

doi:10.21010/ajtcam.v14i3.2

\title{
USING ARTHROSCOPY TO OBSERVE THE EFFECT OF LIVER-SOFTENING MEDICINE ON KNEE OSTEOARTHRITIS
}

\author{
Chong-hua Dai ${ }^{2}$, Jun Sun ${ }^{1 *}$, Xin-feng Gu${ }^{1}$, Yu-xin Zheng ${ }^{1}$ \\ ${ }^{1}$ Shuguang Hospital Affiliated to Shanghai University of Traditional Chinese Medicine, Shanghai 200021, \\ China. ${ }^{2}$ Luliang County People's Hospital, Qujing City, Yunnan Province 655600, China.
}

\section{Corresponding Author Email: drsunjun@163.com}

\begin{abstract}
Background: Arthroscopy was used to observe the clinical effect of liver-softening medicine for treating knee osteoarthritis (OA).

Materials and Methods: Forty knee OA patients with cartilage classifications of Outerbridge grade II, III, or II plus III determined via arthroscopy were randomly assigned to a treatment of liver-softening medicine plus glucosamine or a control treatment of glucosamine alone. Clinical observation and determination of the comprehensive effect score were performed at 60, 120, and 180 days. A second arthroscopy was performed at 180 days.

Results: Signs and symptoms significantly improved at different time points in the treatment group. The effects in the treatment group were better than those in the control group. When analyzing the cartilage during the second arthroscopy, no further degeneration was observed.

Conclusions: After arthroscopic debridement, the treatment of knee OA with liver-softening medicine in conjunction with glucosamine is a feasible and effective solution.
\end{abstract}

Key words: osteoarthritis, arthroscopic debridement, liver-softening medicine

\section{Introduction}

In the treatment of osteoarthritis (OA), the main problems that must be solved are reducing pain, slowing and preventing further development of $\mathrm{OA}$, protecting joint function, and improving the quality of life of patients. Individualized treatment is necessary (Dubin, 2016; Glyn-Jones et al., 2015; Goldring and Berenbaum, 2015). Specific circumstances should be fully considered, such as the risk factors of patients, diseased area, degree of inflammation, pain situation, and concomitant diseases (Bloch et al., 2015; Cherian et al., 2016). The treatment principle has remained predominantly non-drug therapy combined with drug therapy. Surgical intervention can be performed if necessary. For the drug therapy, non-steroidal anti-inflammatory drugs and cartilage-protecting agents are mainly used in Western medicine (Kongtharvonskul et al., 2015; Richette et al., 2015).

However, in traditional Chinese medicine (TCM), OA is known as the Bi syndrome (painful obstruction), which means that either the limbs or the joints are suffering from pain and malfunction, and herb therapy has long been a standard treatment (Cao et al., 2005). TCM usually initiates therapy using kidney-softening and liver-softening supplements based on syndrome differentiation (Han et al., 2010; Li et al., 2011; Li et al., 2014; Mei et al., 2016; Zheng et al., 2015). The liver-softening TCM named Yang Xue Ruan Jian (blood-nourishing and hard-softening) capsule (YXRJC), which is an extract derived from Bai Shao (radix paeoniae alba), Mu Li (concha ostreae), Qin Jiao (radix gentianae macrophyllae) and Gan Cao (radix glycyrrhizae), is a traditional Chinese herb containing mainly paconiflorin and gentianine that is used for the symptomatic treatment of inflammation and pain in OA (Cao et al., 2005). YXRJC is 12 


\section{Dai et al., Afr J Tradit Complement Altern Med., (2017) 14 (3): 12-21}

doi:10.21010/ajtcam.v14i3.2

the hospital preparation of Shuguang Hospital, which is affiliated with Shanghai University of TCM. There have already been clinical studies and applications. Improvements in the symptoms of OA have been confirmed (Cao et al., 2004; Cao et al., 2004; Shi et al., 1994; Shi et al., 2003). To further study liver-softening TCM, we used knee arthroscopy as a means. Arthroscopic debridement and a secondary arthroscopic procedure were performed.

Arthroscopic debridement includes lavage, loose body removal, osteophytes removal, partial meniscus resection, articular surfaces smoothing and adhesion release (Shin and Lee, 2012). Although all of the above contribute to the relief of short-term clinical symptoms in the early phases of OA, the further development of the disease could not be blocked. The efficacy of arthroscopic debridement has been questioned, especially in arthroscopic management of the knee (Pitta et al., 2016). Many studies appraised knee arthroscopy for the treatment of arthritis (Katz et al., 2013; Kirkley et al., 2008; Moseley et al., 2002; Steadman et al., 2013). The recommendations regarding the contribution of knee arthroscopy to OA are not clear (Marsh et al., 2016). Recent studies identified the role played by arthroscopy in the early management of OA (Pitta et al., 2016; Shin and Lee, 2012). With suitable patient choice and reasonable expectations being held by both the patient and surgeon, arthroscopy may lead to symptom relief and functional improvement in OA patients.

In our study, combined with the evaluation of clinical effect, a comparative study of liver-softening TCM was performed to obtain relevant information to improve the evidence supporting the use of liver-softening TCM for the treatment of OA. Simultaneously, the effect of arthroscopic debridement for the treatment of OA was also explored.

\section{Materials and Methods}

General information

This study included 40 patients ( 24 men and 16 females) with a mean age of 57.2 years (range of 46 to 70 years). In accordance with the inclusion criteria and exclusion criteria, the patients exhibited clinical manifestations of knee pain and aggravation of pain under the circumstances of walking up and down stairs or long-distance walking, which may be accompanied by stiffness, swelling and lower-limb fatigue.

\section{Inclusion criteria}

The inclusion criteria were consistent with the diagnostic criteria of Western medicine and TCM syndrome differentiation of the knee disease. The diagnostic criteria of Western medicine refer to the diagnostic criteria for OA of the knee in the "OARSI guidelines for the non-surgical management of knee OA," developed by Osteoarthritis Research Society International (OARSI) (McAlindon et al., 2014). TCM syndrome differentiation is based on TCM syndrome differentiation and treatment of knee paralysis (knee OA) developed by the State Administration of TCM (Huang et al., 2014). The radiographic severity was grade III or less and was quantified using an overall severity grade (Kellgren and Lawrence grade (KL)) (Altman et al., 1995). The grades of cartilage as determined via recent arthroscopy were grade II, grade III, or grade II plus III according to the Outerbridge classification system (Outerbridge, 1961). Informed consent was granted by the patients.

\section{Exclusion criteria}

The exclusion criteria included pregnant and lactating women; patients under 40 years old or more than 70 years old; patients with YXRJC or a glucosamine sulfate capsules allergy, primary synovitis, bone tuberculosis, a bone tumor, pigment villonodular synovitis, serious cardio cerebral vascular and hematopoietic system disease, mental disease, abnormal liver function, a history of skin allergies, a history of long-term use of other drugs that may influence the effect and safety; and patients who participated in other clinical trials within three months. 
A randomized, double-blind controlled clinical trial, was performed. Forty cases were selected and randomly divided into 2 groups, with 20 cases in each group. There was no significant difference between the two groups in terms of age or disease course. In the treatment group, 2 capsules of glucosamine sulfate and 3 YXRJCs were taken by mouth 3 times daily. In the control group, 2 capsules of glucosamine sulfate and 3 starch capsules were taken by mouth 3 times daily. The glucosamine sulfate capsule (Yi Suojia), $0.314 \mathrm{~g} * 24 /$ box, was produced by Zhejiang Hisun Pharmaceutical Co., Ltd., Zhejiang Province, China under the state medical permit No. H20041316. The YXRJC, 0.35 $\mathrm{g} * 60$ / box, was a hospital preparation produced by Shuguang Hospital, which is affiliated with Shanghai University of TCM, with the drug approval number of the Shanghai medicine system Z04100932. Each capsule contained $0.21 \mathrm{~g}$ drugs and $0.14 \mathrm{~g}$ excipients. Arthroscopic debridement was performed on all patients before they were enrolled. In the operation, the cartilage with the Outerbridge grade II, grade III, or grade II plus III could be observed and recorded. The degenerative cartilage was not treated. Anteroposterior and lateral X-ray films of the standing position knee joint were taken and properly graded using the KL grade system. Patients were required to complete the Western Ontario and McMaster Universities Arthritis Index (WOMAC) questionnaire before the operation. All the patients took the oral medicine for 180 days. At days 60, 120 and 180, patients were requested to participate in follow-up visits and complete the WOMAC questionnaire. The arthroscopic procedure was performed again at day 180 .

\section{Concomitant therapy and medication}

Massage, acupuncture and Chinese herbal patch therapy were used simultaneously in both groups. Massage was completed according to the following methods. First, relaxing the quadriceps femoris, pointing, kneading and strumming the start and end points of the muscles around the knee joint were performed in a supine position. Pointing and pressing the double eyes of the knee and patellofemoral joint space while stretching and flexing the knee followed. Finally, pointing and kneading the points of Weizhong, Chengshan, Yinmen, and Kunlun were performed in the prone position. The acupuncture points were mainly the medial knee eye, medial and superior knee eye, exterior knee eye, and exterior and superior knee eye. The needle penetrated 1-1.5 inch into the joint cavity. The warm needling method was also used. A herbal patch with the function of promoting blood circulation to relieve pain was selected. All patients were prohibited from using oral nonsteroidal anti-inflammatory drugs or corticosteroid injections.

\section{Assessment of therapeutic effects}

The methods comprised a comparison of the Outerbridge grades of cartilage under arthroscopy and WOMAC scores before and after the treatment. The WOMAC subscales include pain ( 5 items), stiffness ( 2 items) and physical functioning (17 items). Each item is scored from 0 to 4, yielding a score range of 0-20, 0-8 and 0-68 for the pain, stiffness and physical functioning subscales, respectively (Bellamy et al., 1988). In addition, comprehensive evaluation of the effect was performed at 180 days after the treatment, including a self-evaluation of the effect by the patients using a five-point Likert score (5 points method, 0: very poor; 1: poor; 2: general; 3: good; 4: very good) and a therapeutic effect evaluation by the doctors using a five-point Likert score ( 5 points method, 0 : very poor; 1 : poor; 2 : general; 3: good; 4: very good) (Likert and Rensis, 1932).

\section{Statistical evaluation}

The data analysis was performed using the SAS version 6.12 statistical software package to perform two-factor mixed-design analysis of variance. 
Dai et al., Afr J Tradit Complement Altern Med., (2017) 14 (3): 12-21

doi:10.21010/ajtcam.v14i3.2

\section{Results}

Comparison of the two groups after treatment with arthroscopic cartilage grading

The degenerative cartilage grading under arthroscopy before and after the treatment revealed that no changes occurred in the recorded cartilage grading for both the treatment group and control group. The results meant that there was no further aggravation of cartilage degeneration.

\section{Comparison of the WOMAC scores of the two groups at different time points}

The analysis of variance of repeated-measures data in a two-factor mixed design (see Table 1 and Table 2) revealed that the main effects of the within-subject factor (time) on WOMAC total score, pain score, stiffness score and physical function score were statistically significant $(\mathrm{P}<0.05)$. The main effects of the between-group factor (Group) on the WOMAC total score, stiffness score and physical function score were statistically significant $(\mathrm{P}<0.05)$. The main effects on the WOMAC pain score were not statistically significant ( $\mathrm{P}>0.05)$. Simple effect analysis results (see Table 3 ) revealed that comparing the WOMAC total score, pain score, stiffness score and physical function score of the two groups, there were no statistically significant $(\mathrm{P}>0.05)$ differences between before treatment and at the end of 60 days of treatment. The WOMAC total score, pain score, stiffness score and physical function score of the treatment group were significantly less than those of the control group $(\mathrm{P}<0.05)$ at the end of both 120 and 180 days of treatment. The results indicated that the WOMAC total score, pain score, stiffness score and physical function score of the two groups decreased gradually and significantly as the treatment time prolonged. The long-term effect of the treatment group was superior to that of the control group.

Table 1: Main effects of the within-subject factor (time) (Greenhouse-Geisser correction)

\begin{tabular}{llllllll}
\hline Indicator & $\begin{array}{l}\text { Source } \\
\text { Difference }\end{array}$ & $\begin{array}{l}\text { Sum } \\
\text { Squares } \\
\text { Deviations }\end{array}$ & $\begin{array}{l}\text { of } \\
\text { of }\end{array}$ & $\begin{array}{l}\text { Degree of } \\
\text { Freedom }\end{array}$ & $\begin{array}{l}\text { Mean } \\
\text { Square }\end{array}$ & F value & P \\
& & & & & value \\
\hline WOMAC total score & Time & 69495.469 & 1.396 & 49772.312 & 423.222 & 0.000 \\
& Time*Group & 3717.469 & 1.396 & 2662.433 & 22.639 & 0.000 \\
& Error & 6239.813 & 53.058 & 117.603 & & \\
WOMAC pain score & Time & 5479.450 & 1.872 & 2926.482 & 381.843 & 0.000 \\
& Time*Group & 218.750 & 1.872 & 116.831 & 15.244 & 0.000 \\
\multirow{2}{*}{ WOMAC stiffness } & Error & 545.300 & 71.150 & 7.664 & & \\
score & Time & 1174.850 & 1.267 & 927.273 & 257.910 & 0.000 \\
& & & & & & \\
\multirow{2}{*}{$\begin{array}{l}\text { WOMAC } \\
\text { function score }\end{array}$} & Time*Group & 77.550 & 1.267 & 61.208 & 17.024 & 0.000 \\
& Error & 173.100 & 48.146 & 3.595 & & \\
& Time & 24235.050 & 1.676 & 14457.824 & 211.892 & 0.000 \\
& & & & & & \\
\hline
\end{tabular}


Dai et al., Afr J Tradit Complement Altern Med., (2017) 14 (3): 12-21

doi:10.21010/ajtcam.v14i3.2

Table 2: Main effects of the between-group factor (Group))

\begin{tabular}{lllllll}
\hline Indicator & $\begin{array}{l}\text { Source of } \\
\text { Difference }\end{array}$ & $\begin{array}{l}\text { Sum of } \\
\text { Squares of } \\
\text { Deviations }\end{array}$ & $\begin{array}{l}\text { Degree } \\
\text { of }\end{array}$ & $\begin{array}{l}\text { Mean } \\
\text { Square }\end{array}$ & F value & P value \\
\hline WOMAC total score & Group & 3696.006 & 1 & 3696.006 & 8.695 & 0.005 \\
& Error & 16152.438 & 38 & 425.064 & & \\
WOMAC pain score & Group & 211.600 & 1 & 211.600 & 1.595 & 0.214 \\
& Error & & 38 & & & \\
WOMAC stiffness score & Group & 202.500 & 1 & 202.500 & 4.275 & 0.046 \\
& Error & 1799.900 & 38 & 47.366 & & \\
WOMAC physical & Group & 1030.225 & 1 & 1030.225 & 24.235 & 0.000 \\
function score & & & & & & \\
& Error & 1615.375 & 38 & 42.510 & & \\
\hline
\end{tabular}

Table 3: Comparison of the WOMAC scores of the two groups at different time points $\left(\bar{x}_{ \pm \mathrm{S}}\right)$ Remarks: For the same group, comparison of time points with different right superscript letters, $\mathrm{P}<0.05$. For the same group, comparison of groups with same right superscript letters (*\#), $\mathrm{P}>0.05$; comparison of groups with different right superscript letters (*\#), $\mathrm{P}<0.05$.

\begin{tabular}{|c|c|c|c|c|c|c|c|c|c|}
\hline \multirow{2}{*}{ Group } & \multirow{2}{*}{$n$} & \multicolumn{4}{|c|}{ WOMAC total score } & \multicolumn{4}{|c|}{ WOMAC pain score } \\
\hline & & Baseline & $60 \mathrm{~d}$ & $120 \mathrm{~d}$ & $180 \mathrm{~d}$ & Baseline & $60 \mathrm{~d}$ & $120 \mathrm{~d}$ & $180 \mathrm{~d}$ \\
\hline Control & 20 & $129.3 \pm 18.6^{6^{*}}$ & $108.5 \pm 12.7^{b^{*}}$ & $100.5 \pm 7.0^{\mathrm{c}^{*}}$ & $83.9 \pm 5.2^{\mathrm{d}^{*}}$ & $\begin{array}{l}28.3 \pm 7.6 \\
\mathrm{a}^{*}\end{array}$ & $\begin{array}{l}22.1 \pm 6.8 \\
b^{*}\end{array}$ & $\begin{array}{l}19.5 \pm 5.2 \\
c^{*}\end{array}$ & $\begin{array}{l}15.3 \pm 4.0 \\
\mathrm{~d}^{*}\end{array}$ \\
\hline Treatment & 20 & $130.9 \pm 19.3^{3^{*}}$ & $106.5 \pm 12.5^{b^{*}}$ & $83.5 \pm 6.9^{\mathrm{c \#}}$ & $62.7 \pm 4.3^{\mathrm{d} \#}$ & $\begin{array}{l}29.1 \pm 6.2 \\
\mathrm{a}^{*}\end{array}$ & $\begin{array}{l}21.2 \pm 7.3 \\
b^{*}\end{array}$ & $\begin{array}{l}15.2 \pm 6.5 \\
\text { c\# }\end{array}$ & $\begin{array}{l}10.4 \pm 3.4 \\
\text { d\# }\end{array}$ \\
\hline \multirow{2}{*}{ Group } & \multirow{2}{*}{$n$} & \multicolumn{4}{|c|}{ WOMAC stiffness score } & \multicolumn{4}{|c|}{ WWOMAC physical function score } \\
\hline & & Baseline & $60 d$ & $120 \mathrm{~d}$ & $180 \mathrm{~d}$ & Baseline & $60 d$ & $120 \mathrm{~d}$ & $180 \mathrm{~d}$ \\
\hline Control & 20 & $14.6 \pm 4.6^{\mathrm{a}^{*}}$ & $11.0 \pm 4.1^{\mathrm{b}^{*}}$ & $10.7 \pm 3.6^{\mathrm{c}^{*}}$ & $8.4 \pm 2.1^{\mathrm{d}^{*}}$ & $\begin{array}{l}86.4 \pm 7.8 \\
a^{*}\end{array}$ & $\begin{array}{l}75.4 \pm 6.7 \\
b^{*}\end{array}$ & $\begin{array}{l}70.3 \pm 4.9 \\
c^{*}\end{array}$ & $\begin{array}{l}60.2 \pm 3.4 \\
d^{*}\end{array}$ \\
\hline Treatment & 20 & $13.2 \pm 4.2^{\mathrm{a}^{*}}$ & $10.6 \pm 3.6^{b^{*}}$ & $7.5 \pm 3.4^{\mathrm{c \#}}$ & $4.4 \pm 2.5^{\mathrm{d} \#}$ & $\begin{array}{l}88.6 \pm 9.7 \\
a^{*}\end{array}$ & $\begin{array}{l}74.7 \pm 6.5 \\
b^{*}\end{array}$ & $\begin{array}{l}60.8 \pm 4.5 \\
\text { c\# }\end{array}$ & $\begin{array}{l}47.9 \pm 2.5 \\
\text { d\# }\end{array}$ \\
\hline
\end{tabular}

Comparisons of the effect self-evaluated by patients and the therapeutic effect evaluated by doctors between the two groups

Based on a t-test of two sample means, the self-evaluated effect scores in the treatment group (3.55 \pm 0.51$)$ were significantly better than those in the control group $(2.55 \pm 0.68)(\mathrm{P}<0.05)$. The therapeutic effect scores in the treatment group $(3.65 \pm 0.49)$ were also significantly better than those in the control group $(2.85 \pm 0.49)(\mathrm{P}<0.05)$.

\section{Discussion}

In aging populations, effective treatment of knee $\mathrm{OA}$ in the elderly is one of the main research topics (Bannuru et al., 2015; Gelber, 2015). This study is based on the arthroscopic treatment of knee OA with TCM. The study both observed the effect of arthroscopy on knee OA and used arthroscopy to evaluate the effect of the liver-softening TCM 


\section{Dai et al., Afr J Tradit Complement Altern Med., (2017) 14 (3): 12-21}

doi:10.21010/ajtcam.v14i3.2

named YXRJC.

Arthroscopic debridement, as a minimally invasive technique, has the advantages of open surgery in the treatment of knee OA because of the small operation wound and fast recovery. Arthroscopic debridement has become the "transfer station" of the conservative treatment of knee OA and joint replacement surgery, which have been paid increasingly more attention by clinicians (Katz et al., 2014). However, arthroscopic debridement is a palliative procedure to improve symptoms and delay progression of the disease. Although it has been used in clinical practice for several decades, and the effect is significant for some patients, there has been a new debate about whether arthroscopic debridement is effective in recent years (Adams, 2014; Krych et al., 2013; Siparsky et al., 2007). The American College of Rheumatology (ACR), American Academy of Orthopaedic Surgeons (AAOS), and Osteoarthritis Research Society International (OARSI) have published OA treatment guidelines over the past few years (Katz et al., 2014). The guidelines developed by professional organizations and insurance companies did not encourage use of arthroscopic debridement to treat knee OA. The role of arthroscopy for OA treatment is still a controversial issue. More recent evidence suggests that properly selected patients may benefit from arthroscopy (Pitta et al., 2016; Shin and Lee, 2012). Built on the review of clinical studies, the recommended indications for knee arthroscopic debridement are hydroarthrosis, localized joint line tenderness, acute or aggravating catching or locking, development or aggravation of symptoms related to a specific injury mechanism, loose body, and early stage degenerative arthritis. Currently, there is still controversy regarding whether arthroscopic debridement has a placebo effect. We believe that OA is a degenerative change with age that is inevitable. Debridement of OA can improve pain symptoms in patients, but it is not possible to solve the fundamental problem of joint degeneration. Therefore, we performed a selective and limited cleaning during the operation to reduce the joint disturbance. The flushing of the joint cavity was enhanced to reduce inflammatory factors such as interleukins and prostaglandins. We cleaned the stripped cartilage debris, repaired the articular cartilage and meniscus, resected the function-affected osteophytes, and released the patellar retinaculum to reduce the pressure of the patellofemoral articular surface and improve the joint function. Simultaneously, supportive physical therapy and drug therapy were applied to enhance the long-term curative effect.

Glucosamine is one of the disease-modifying osteoarthritis drugs (DMOADs) with different and even contradictory treatment conclusions. Experts views and guidelines are not yet consistent. The European League Against Rheumatism (EULAR) Recommendations 2003 (Jordan et al., 2003) and OARSI Recommendations 2010 (Zhang et al., 2010) both recommended glucosamine as a DMOAD to improve OA symptoms. In 2012, the ACR guidelines (Hochberg et al., 2012) did not recommend glucosamine because they noted that glucosamine is not a prescription drug in the USA but rather only a dietary supplement, whose quality has not been evaluated by the Food and Drug Administration (FDA). The updated OARSI guidelines 2014 (McAlindon et al., 2014) stated that the recommendation of glucosamine was uncertain for symptom relief and not appropriate for disease modification. The main reason was the consideration by some experts of the lack of sufficient evidence-based research into the effects of glucosamine as a non-prescription drug. In addition, there were obvious distinctions between the efficacy in clinical practice and in rigorously designed clinical studies. Experts also note that "uncertain" does not mean a disagreement with the prescription of glucosamine. However, an algorithm recommendation in 2014 of the European Society for Clinical and Economic Aspects of Osteoporosis and Osteoarthritis (ESCEO) (Bruyère et al., 2014) stated that glucosamine sulfate was superior to the placebo in the treatment of pain and functional impairment with the effect size of 0.27 (95\% CI: 0.12-0.43) on pain and 0.33 (95\% CI: $0.17-0.48$ ) on function. Long-term prescription glucosamine sulfate might delay joint structure changes, suggesting potential benefit beyond symptom control when used early in the management of OA. In addition to its efficacy record, glucosamine sulfate is a safe medication with no difference in adverse effects compared with placebo, which strengthens the argument for its use as a chronic background treatment. Because ethics does not allow using a placebo alone as a control in clinical trials with periods of 6 months or more, we prescribed glucosamine in both the treatment and control groups. YXRJC is a prescription of TCM, and its mechanism is different from that of glucosamine. The purpose of this study was not to investigate glucosamine but rather to determine the 17 


\section{Dai et al., Afr J Tradit Complement Altern Med., (2017) 14 (3): 12-21}

doi:10.21010/ajtcam.v14i3.2

efficacy of and adverse reactions to YXRJC on the basis of glucosamine treatment.

Professor Shi Yin-yu (Cao et al., 2006) believes that knee OA is a root of wilting and tip of impediment, coexistence of impediment and wilting. Under the guidance of this thought for the treatment of OA, the kidney and liver should be soft, and nourishing blood is also needed. The ingredients of liver-softening TCM named YXRJC are Bai Shao (radix paeoniae alba), Mu Li (concha ostreae), Qin Jiao (radix gentianae macrophyllae) and Gan Cao (radix glycyrrhizae); these serve the function of nourishing and activating blood, and softening hard and dredging collaterals. Bai Shao belongs to the liver meridian, with the actions of preserving Yin to nourish blood, soften the liver, and relieve pain. $\mathrm{Mu} \mathrm{Li}$ belongs to the liver, kidney and lung meridian, with the actions of calming the liver and subduing Yang, quieting the spirit with heavy settlers, dissolving hard lumps, and inducing astringency. Qin Jiao belongs to the liver, stomach and gallbladder meridian, with the actions of expelling wind, removing dampness, relaxing the muscles and stimulating blood circulation. Gan Cao reconciles other drugs. Past studies have found that the liver-softening medicine has a better effect on delaying the degradation of cartilage in the early and late stages of OA ( $\mathrm{Li}$ et al., 2011; Li et al., 2014; Zheng et al., 2015). The liver-softening medicine also has certain inhibitions on synovitis (Han et al., 2010; Mei et al., 2016). It can promote the synthesis of DNA in cartilage cells, collagen and protein of the cartilage (Chen et al., 2014; Yuan et al., 2012). It has a protective effect on cartilage during the course of OA. One of the mechanisms for the prevention and treatment of OA may be to reduce the COMP expression of cartilage matrix protein in the synovial tissue, which can delay the pathological process of OA (Cao et al., 2007; Feng et al., 2001; Shi et al., 2007; Zhang et al., 2008). Treatment of OA with liver-softening medicines has been supported by some academic research and aroused extensive attention (Chen et al., 2014; Yuan et al., 2012). This study found that at the second arthroscopic observation of the Outerbridge grade II or III degenerative cartilage, there was no further aggravation of degeneration in either the YXRJC and glucosamine sulfate group or pure glucosamine sulfate group, which indicates that both YXRJC and glucosamine sulfate can postpone cartilage degeneration. The WOMAC total score further indicated that the liver-softening medicine YXRJC had a good clinical curative effect in the medium term, especially at 120 days and 180 days.

In summary, treatment of knee OA with arthroscopic surgery combined with the liver-softening medicine YXRJC and glucosamine sulfate is a feasible and effective method. Of course, this study is limited by the small number of cases. The main reason for this small number is the patients' low rate of acceptance of the second arthroscopic surgery. In addition, OA patients with the KL classification standard grade IV and above were not included in this study. We believe that in the condition of the existing large osteophytes and joint space narrowing in the KL grade IV or above, knee arthroscopic debridement is unable to remove the large intraarticular osteophytes with a good therapeutic effect. Additionally, there were no observations and analysis of Outerbridge grade IV cartilage under arthroscopy in this study. Outerbridge grade IV cartilage has deep cortical degeneration, full-thickness cartilage defect, and subchondral bone exposure. In this case, the effect of conventional arthroscopic debridement, drilling, micro fracture and grinding is often poor. For such patients, drug treatment should be based on anti-inflammatory and analgesic drugs. Total knee arthroplasty is usually the best choice.

\section{Conclusions}

After arthroscopic debridement, treatment of knee OA with liver-softening medicine associated with glucosamine is a feasible and effective solution. The treatment received satisfactory mid-term curative results. The application of the liver-softening medicine YXRJC reflects that TCM combined with modern medicine has bright prospects.

\section{Conflict of interest}

No conflict of interest declared. 


\section{References}

1. Adams, J.E. (2014). Does arthroscopic débridement with or without interposition material address carpometacarpal arthritis? Clin. Orthop. Relat. Res., 472(4):1166-72.

2. Altman, R.D., Hochberg, M., Murphy, W.A. Jr., Wolfe, F., and Lequesne, M. (1995). Atlas of individual radiographic features in osteoarthritis. Osteoarthritis Cartilage, 3 Suppl A:3-70.

3. Bannuru, R.R., McAlindon, T.E., Sullivan, M.C., Wong, J.B., Kent, D.M., and Schmid, C.H. (2015). Effectiveness and Implications of Alternative Placebo Treatments: A Systematic Review and Network Meta-analysis of Osteoarthritis Trials. Ann. Intern. Med., 163(5):365-72.

4. Bellamy, N., Buchanan, W.W., Goldsmith, C.H., Campbell, J., and Stitt, L.W. (1998). Validation study of WOMAC: a health status instrument for measuring clinically important patient relevant outcomes to antirheumatic drug therapy in patients with osteoarthritis of the hip or knee. J. Rheumatol., 15(12):1833-40.

5. Bloch, B., Srinivasan, S., and Mangwani, J. (2015). Current Concepts in the Management of Ankle Osteoarthritis: A Systematic Review. J. Foot Ankle Surg., 54(5):932-9.

6. Bruyère, O., Cooper, C., Pelletier, J.P., Branco, J., Luisa Brandi, M., Guillemin, F., Hochberg, M.C., Kanis, J.A., Kvien, T.K., Martel-Pelletier, J., Rizzoli, R., Silverman, S., and Reginster, J.Y. (2014). An algorithm recommendation for the management of knee osteoarthritis in Europe and internationally: a report from a task force of the European Society for Clinical and Economic Aspects of Osteoporosis and Osteoarthritis (ESCEO). Semin. Arthritis Rheum., 44(3):253-63.

7. Cao, Y., Shi, Y., Zheng, Y., Shi, M., and Lo, S.K. (2005). Blood-nourishing and hard-softening capsule costs less in the management of osteoarthritic knee pain: a randomized controlled trial. Evid. Based Complement Alternat. Med., 2(3):363-8.

8. Cao, Y.L., Pang, J., Wang, X., Shi, Y., Shen, W.D., Zheng, Y.X., Zhan, H.S., and Shi, Y.Y. (2006). Current status of Chinese herbal therapy for osteoarthritis. Chinese Journal of Clinical Rehabilitation, 10(35):130-134.

9. Cao, Y.L., Shi, W.Z., Xu, Y., Shen, P.Z., and Shi, Y.Y. (2004). Experimental study on the anti-inflammatory and analgesic effects of Yangxue Ruanjian capsule. Acta Universitatis Traditionis Medicalis Sinensis Pharmacologiaeque Shanghai, 18(1):49-51.

10. Cao, Y.L., Wang, X., Feng, W., Wang, S.C., Xu, Y., Zhan, H.S., and Shi, Y.Y. (2007). In vitro study the effect of both extract and compound from liver-softening herbs on chondrocyte proliferation and COMP expression of human osteoarthritis. China Journal of Orthopaedics and Traumatology, 20(6):389-390.

11. Cao, Y.L., Zheng, Y.X., Shi, Y.Y., and Shi, M.Y. (2004). Efficacy study on Yangxue ruanjian jiaonang in the management of osteoarthritic knee with randomized controlled trial. Chinese Remedies \& Clinics, 4(6): 423-427.

12. Chen, H.X., Xu, N.D., Peng, L.P., Xie, Z.J., He, B.B., and Chen, X. (2014). Experimental research progress of traditional Chinese medicine in the treatment of knee osteoarthritis cartilage repair. Modern Journal of Integrated Traditional Chinese and Western Medicine, 23(25):2843-2845.

13. Cherian, J.J., Jauregui, J.J., Leichliter, A.K., Elmallah, R.K., Bhave, A., and Mont, M.A. (2016). The effects of various physical non-operative modalities on the pain in osteoarthritis of the knee. Bone Joint J., 98-B(1 Suppl A):89-94.

14. Dubin, A. (2016). Managing Osteoarthritis and Other Chronic Musculoskeletal Pain Disorders. Med. Clin. North Am., 100(1):143-50.

15. Feng, W., Shi, Y.Y., Shen, P.Z., and Xu, Y. (2001). In Vitro Study of Sera Contained in Bushenfang and Rouganfang (China herbs) on proliferation dynamics of chondrocytes. Journal of Zhejiang Chinese Medical University, 25(4):15-17.

16. Gelber, A.C. (2015). Conventional medical therapy for osteoarthritis: current state of the evidence. Curr. Opin. Rheumatol., 27(3):312-7. 


\section{Dai et al., Afr J Tradit Complement Altern Med., (2017) 14 (3): 12-21}

doi:10.21010/ajtcam.v14i3.2

17. Glyn-Jones, S., Palmer, A.J., Agricola, R., Price, A.J., Vincent, T.L., Weinans, H., and Carr, A.J. (2015). Osteoarthritis. Lancet, 386(9991):376-87.

18. Goldring, M.B., and Berenbaum, F. (2015). Emerging targets in osteoarthritis therapy. Curr. Opin. Pharmacol., 22:51-63.

19. Han, Q.M., Huang, X.D., and Wang, Y.H. (2010). Study on treatment of knee osteoarthritis from kidney, liver and spleen related theory. Journal of Sichuan of Traditional Chinese Medicine, 28(05):35-36.

20. Hochberg, M.C., Altman, R.D., April, K.T., Benkhalti, M., Guyatt, G., McGowan, J., Towheed, T., Welch, V., Wells, G., Tugwell, P.; and American College of Rheumatology. (2012). American College of Rheumatology 2012 recommendations for the use of nonpharmacologic and pharmacologic therapies in osteoarthritis of the hand, hip, and knee. Arthritis Care Res (Hoboken)., 64(4):465-74.

21. Huang, K.D., Liu, X.P., and Huang, Z.R. (2014). Distribution of traditional Chinese medicine syndromes of osteoarthritis of the knee in Nanchang area. Mod. Diagn. Treat, 25(4):744-745.

22. Jordan, K.M., Arden, N.K., Doherty, M., Bannwarth, B., Bijlsma, J.W., Dieppe, P., Gunther, K., Hauselmann, H., Herrero-Beaumont, G., Kaklamanis, P., Lohmander, S., Leeb, B., Lequesne, M., Mazieres, B., Martin-Mola, E., Pavelka, K., Pendleton, A., Punzi, L., Serni, U., Swoboda, B., Verbruggen, G., Zimmerman-Gorska, I., Dougados, M.; and Standing Committee for International Clinical Studies Including Therapeutic Trials ESCISIT. (2003). EULAR Recommendations 2003: an evidence based approach to the management of knee osteoarthritis: Report of a Task Force of the Standing Committee for International Clinical Studies Including Therapeutic Trials (ESCISIT). Ann. Rheum. Dis., 62(12):1145-55.

23. Katz, J.N., Brophy, R.H., Chaisson, C.E., de Chaves, L., Cole, B.J., Dahm, D.L., Donnell-Fink, L.A., Guermazi, A., Haas, A.K., Jones, M.H., Levy, B.A., Mandl, L.A., Martin, S.D., Marx, R.G., Miniaci, A., Matava, M.J., Palmisano, J., Reinke, E.K., Richardson, B.E., Rome, B.N., Safran-Norton, C.E., Skoniecki, D.J., Solomon, D.H., Smith, M.V., Spindler, K.P., Stuart, M.J., Wright, J., Wright, R.W., and Losina, E. (2013). Surgery versus physical therapy for a meniscal tear and osteoarthritis. N. Engl. J. Med., 368(18):1675-84.

24. Katz, J.N., Brownlee, S.A., and Jones, M.H. (2014). The role of arthroscopy in the management of knee osteoarthritis. Best Pract. Res. Clin. Rheumatol., 28(1):143-56.

25. Kirkley, A., Birmingham, T.B., Litchfield, R.B., Giffin, J.R., Willits, KR., Wong, C.J., Feagan, B.G., Donner, A., Griffin, S.H., D'Ascanio, L.M., Pope, J.E., and Fowler, P.J. (2008). A randomized trial of arthroscopic surgery for osteoarthritis of the knee. N. Engl. J. Med., 359(11):1097-107.

26. Kongtharvonskul, J., Anothaisintawee, T., McEvoy, M., Attia, J., Woratanarat, P., and Thakkinstian, A. (2015). Efficacy and safety of glucosamine, diacerein, and NSAIDs in osteoarthritis knee: a systematic review and network meta-analysis. Eur. J. Med. Res., 13;20:24.

27. Krych, A.J., Bert, J.M., and Levy, B.A. (2013). Treatment of OA of the knee in the middle-aged athlete: the role of arthroscopy. Sports Med. Arthrosc., 21(1):23-30.

28. Li, X.H., Chen, W.L., and Liu, X.X. (2011). Study on the mechanism of preventing and treating osteoarthritis by the method of invigorating the kidney and softing the liver. Journal of Fujian University of Traditional Chinese Medicine, 21(2): 66-69.

29. Li, X.H., Liang, W.N., Dang, C.P., Ye, H.Z., Zheng, C.S., Wu, G.W., Xu, H.F., Zhu, X.Q., Zheng, L.P., Huang, Y.M., Chen, W.L., and Liu, X.X. (2014). Empirical study on Bushen Zhuangjin decoction inhibiting inflammatory cytokine expression experiments to delay the degeneration of articular cartilage. Rheumatism and Arthritis, 3(5):20-25.

30. Likert, and Rensis. (1932). A technique for the measurement of attitudes. Archives of Psychology, 1-55.

31. Marsh, J.D., Birmingham, T.B., Giffin, J.R., Isaranuwatchai, W., Hoch, J.S., Feagan, B.G., Litchfield, R., Willits, K., and Fowler, P. (2016). Cost-effectiveness analysis of arthroscopic surgery compared with non-operative management for osteoarthritis of the knee. BMJ Open, 6(1):e009949. 


\section{Dai et al., Afr J Tradit Complement Altern Med., (2017) 14 (3): 12-21}

doi:10.21010/ajtcam.v14i3.2

32. McAlindon, T.E., Bannuru, R.R., Sullivan, M.C., Arden, N.K., Berenbaum, F., Bierma-Zeinstra, S.M., Hawker, G.A., Henrotin, Y., Hunter, D.J., Kawaguchi, H., Kwoh, K., Lohmander, S., Rannou, F., Roos, E.M., and Underwood, M. (2014). OARSI guidelines for the non-surgical management of knee osteoarthritis. Osteoarthritis Cartilage, 22(3):363-88

33. Mei, Y.Y., Fu, C.L., Pang, S.Q., Zheng, L.X., and Zheng, C.S. (2016). Exploration of the mechanism of tonifying the liver and kidney, eliminating wind and wetness of osteoarthritis. Rheumatism and Arthritis, 5(5): 51-54.

34. Moseley, J.B., O'Malley, K., Petersen, N.J., Menke, T.J., Brody, B.A., Kuykendall, D.H., Hollingsworth, J.C., Ashton, C.M., and Wray, N.P. (2002). A controlled trial of arthroscopic surgery for osteoarthritis of the knee. N. Engl. J. Med., 347(2):81-8.

35. Outerbridge, R.E. (1961). The etiology of chondromalacia patella. J. Bone Joint Surg., 43-B:752-57.

36. Pitta, M., Davis, W. 3rd, and Argintar, E.H. (2016). Arthroscopic Management of Osteoarthritis. J. Am. Acad. Orthop. Surg., 24(2):74-82.

37. Richette, P., Latourte, A., and Frazier, A. (2015). Safety and efficacy of paracetamol and NSAIDs in osteoarthritis: which drug to recommend? Expert. Opin. Drug Saf., 14(8):1259-68.

38. Shi, G.T., Han, D.P., Zheng, Y.X., Cao, Y.L., Zhang, P., and Wu, N. (2007). Effect of tonifying kidney and liver nourishing recipe on the expression of COMP gene in the synovium of C57 black rat knee osteoarthritis. Acta Universitatis Traditionis Medicalis Sinensis Pharmacologiaeque Shanghai, 21(3): 55-58.

39. Shi, W.Z., Liu, L., Shen, P.Z., Xu, Y., Xu, D.S., and Shi, Y.Y. (2003). Effects of different extraction methods on chemical component contents and pharmacological actions of Yangxue ruanjian prescription. Traditional Chinese Drug Research and Clinical Pharmacology, 14(2):125-127.

40. Shi, Y.Y., Xu, S.R., and Chen, Y.H. (1994). The clinical report of Yangxue Ruanjian decoction in the treatment of knee osteoarthritis. Chinese Journal of Traditional Medical Traumatology \& Orthopedics, 2(4):33-36.

41. Shin, C.S., and Lee, J.H. (2012). Arthroscopic treatment for osteoarthritic knee. Knee Surg. Relat. Res., 24(4):187-92.

42. Siparsky, P., Ryzewicz, M., Peterson, B., and Bartz, R. (2007). Arthroscopic treatment of osteoarthritis of the knee: are there any evidence-based indications? Clin. Orthop. Relat. Res., 455:107-12.

43. Steadman, J.R., Briggs, K.K., Matheny, L.M., and Ellis, H.B. (2013). Ten-year survivorship after knee arthroscopy in patients with Kellgren-Lawrence grade 3 and grade 4 osteoarthritis of the knee. Arthroscopy, 29(2):220-5.

44. Yuan, Q., Kan, W.B., Song, P.F., Xie, D.H., Jiang, Y.X., and Wang, Y.Y. (2012). Basic research for treatment of osteoarthritis with Chinese medicine. Journal of Liaoning University of Traditional Chinese Medicine, 14(1):101-104.

45. Zhang, P., Shi, G.T., Zheng, Y.X., and Cao, Y.L. (2008). Effect of Invigorating Kidney Formula, Softening Liver Formula and Dissipating Phlegm Formula on Synoviocyte Proliferation and COMP Expression in Knee Osteoarthritis. Chinese Journal of Traditional Medical Traumatology \& Orthopedics, 16(12):18-21.

46. Zhang, W., Nuki, G., Moskowitz, R.W., Abramson, S., Altman, R.D., Arden, N.K., Bierma-Zeinstra, S., Brandt, K.D., Croft, P., Doherty, M., Dougados, M., Hochberg, M., Hunter, D.J., Kwoh, K., Lohmander, L.S., and Tugwell, P. (2010). OARSI recommendations for the management of hip and knee osteoarthritis: part III: Changes in evidence following systematic cumulative update of research published through January 2009. Osteoarthritis Cartilage, 18(4):476-99.

47. Zheng, C.S., Ye, H.Z., Li, X.H., Ye, J.X., Wu, G.W., Xu, X.J., and Liu, X.X. (2015). Comparison of the mode of action of Bushen rougan drugs versus Huoxue Qufeng drugs contained in Tougu Xiaotong Jiaonang for the treatment of osteoarthritis: A computer simulation study. The Journal of Traditional Chinese Orthopedics and Traumatology, 27(7):6-10. 